\title{
The Chlorpropamide Alcohol Flush
}

\section{Lack of Specificity for Familial Non-insulin Dependent Diabetes}

\author{
J. Köbberling, N. Bengsch, B. Brüggeboes, H. Schwarck, H. Tillil, and M. Weber \\ Department of Medicine, University of Göttingen, Göttingen, FRG
}

Summary. A facial flush provoked by alcohol in chlorpropamide treated diabetics has been described as a genetic marker for a dominantly inherited type of non-insulin dependent diabetes. In this study a chlorpropamide alcohol flush was observed in $16.9 \%$ of control subjects $(\mathrm{n}=154), 23.3 \%$ of insulin dependent diabetics $(\mathrm{n}=437)$ and $16.5 \%$ of patients with non-insulin dependent diabetes $(\mathrm{n}=$ 145). Among the non-insulin dependent diabetics no difference in the frequency of the chlorpropamide alcohol flush was found between those with and without a family history of diabetes. Specificity was not improved by skin temperature measurement or additional placebo tests. According to these data the chlorpropamide alcohol flush does not seem to be specific for non-insulin dependent diabetes and hypotheses about the aetiology of this type of diabetes based on the chlorpropamide alcohol flush should be regarded with caution.

Key words: Chlorpropamide alcohol flush, non-insulin dependent diabetes, insulin dependent diabetes, MODY, genetics, HLA-types.

Leslie and Pyke [1] have reported a facial flush reaction provoked by small amounts of alcohol in patients given chlorpropamide. The authors suggest this chlorpropamide alcohol flush (CPAF) as genetic marker for a special type of non-insulin dependent diabetes (NIDDM) with autosomal dominant inheritance [2], including the so called MODY and comprising about $20 \%$ of all diabetics. The test was positive in $31 \%$ of NIDDM without, and $81 \%$ of NIDDM with a family history of diabetes but only in $10 \%$ of normal subjects and $10 \%$ of insulin depend- ent diabetics (IDDM). Within the diabetic families the flush reaction followed the transmission of NIDDM, and a positive flush test in non diabetic family members was regarded as a risk factor. Furthermore, the CPAF has given rise to hypotheses about the aetiology of NIDDM $[3,4]$.

Following this line defined groups of diabetics have been investigated to check the association of CPAF with special types of diabetes. In a second part of the study specificity and reproducibility of CPAF were tested using objective test evaluation by facial skin temperature measurements.

\section{Subjects and Methods}

CPAF-tests were performed as described by Leslie and Pyke [1]. The subjects received $250 \mathrm{mg}$ (one tablet) of chlorpropamide $12 \mathrm{~h}$ and $36 \mathrm{~h}$ before administration of $20 \mathrm{ml}$ of dry sherry $(18 \%$ alcohol). Tests were performed 1 to $2 \mathrm{~h}$ after after the last meal, usually after breakfast. One hour after sherry ingestion the subjects, who did not know what reaction was expected, were asked to answer a questionnaire with a list of several possible reactions among which "hot feeling in the face" (in German: "Hitzeempfindungen im Gesicht") was regarded as positive. In accordance with Leslie and Pyke [1] a visible flush was not regarded as a prerequisite for a positive test but only the patients' subjective description. Placebo tests were not performed in this series.

The control subjects were either students and young teachers $(\mathrm{n}=101)$ or non diabetic relatives of patients with IDDM $(\mathrm{n}=$ 53). Patients with IDDM (ketosis prone, insulin treatment within half a year after diagnosis) were recruited from 5 different studies each of which was performed independently by one investigator:
A: patients from a diabetic clinic $(n=54)$,
$B$ : patients with age at onset $<25$ years from a summer camp for juvenile diabetics $(n=47)$,
C: patients from an earlier study on HLA association [5] $(\mathrm{n}=90)$,
D: female patients with IDDM from an earlier study on the dia- betes risk for their children [6] $(n=198)$,
E: subjects with IDDM with an age at onset $\supseteq 25$ years $(n=48)$. 
No special selection was performed in all these groups other than that stated above. The consent of the patients was required, however, and was obtained in about $75 \%$ of all requested. From patients with IDDM who turned out to be CPAF-positive HLA antigens were determined if the individuals agreed to a venepuncture $(n=49)$.

Fourteen patients from 5 different families had typical MODY (Tattersall syndrome $[7,8]$ ) with early onset, lack of ketoacidosis, lack of diabetic complications, and with family members with a similar type of diabetes. In three of these families, including the family shown in Figure 1, all affected members had a low renal threshold for glucose, as was described by Tattersall in two of his three original families [7], including the Mason-family reported to be CPAF-positive [4].

Patients with NIDDM and age at onset between 25 and 75 years were grouped into those without $(n=69)$ and with $(n=62)$ a family history of NIDDM (at least one first degree relative).

In a second series on 21 controls, 8 previously flush positive subjects with IDDM, 4 MODY's, and 10 NIDDM patients with a positive family history additional tests with placebo as well as with chlorpropamide were performed. In eight of these patients either

Table 1. Percentage of CPAF-positive subjects (subjective evaluation by questionnaire) amongst groups of normal individuals, insulin-dependent diabetics (IDDM), Tattersall Syndrome (MODY) $(7,8)$, and non-insulin-dependent diabetics (NIDDM). For explanation of groups A-E see Methods

\begin{tabular}{|c|c|c|c|c|c|}
\hline & & $\mathrm{n}$ & & $\%$ po & \\
\hline $\mathrm{I}$ & Normal individuals & & 154 & & 16.9 \\
\hline II & $\begin{array}{l}\text { IDDM } \\
\text { A } \\
\text { B } \\
\text { C } \\
\text { D } \\
\text { E }\end{array}$ & $\begin{array}{r}54 \\
47 \\
90 \\
198 \\
48\end{array}$ & 437 & $\begin{array}{l}25.9 \\
23.4 \\
18.9 \\
23.2 \\
29.2\end{array}$ & 233 \\
\hline III & MODY & & 14 & & 28.6 \\
\hline IV & $\begin{array}{l}\text { NIDDM (other than MODY } \\
\text { a) without family history } \\
\text { b) with family history } \\
\text { Sum }\end{array}$ & $\begin{array}{r}69 \\
62\end{array}$ & 131 & $\begin{array}{l}13.0 \\
17.7\end{array}$ & 15.3 \\
\hline
\end{tabular}

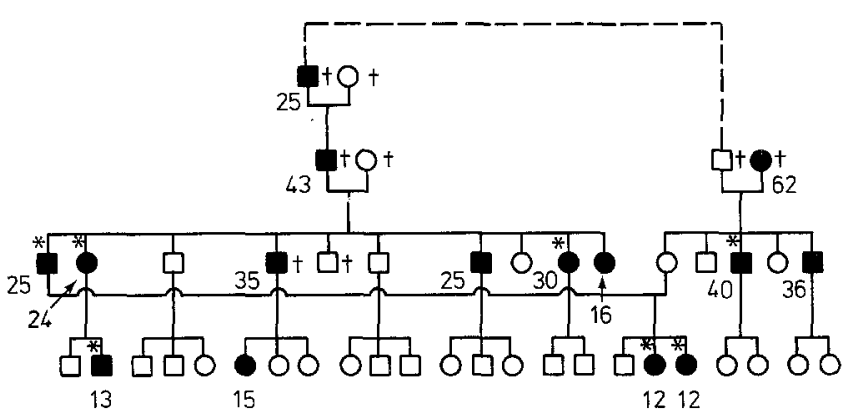

Fig. 1. Pedigree of a family with typical MODY (Tattersall syndrome). Age at onset of diabetes is given for all affected members. Patients in whom CPAF-tests were performed are indicated by an asterisk. All tests were negative the placebo test or the chlorpropamide test was performed twice. Facial skin temperature was measured continuously with a small temperature sensor probe fixed with adhesive tape over the cheeks, and a Technoterm 5500 digital thermometer (Testoterm $\mathrm{KG}$, Lenzkirch, Germany). Room temperature was kept constant at $20^{\circ} \mathrm{C}$ and the sherry was only given after acclimatisation and at least 20 min. of constant skin temperature. An increase of facial skin temperature of $1.2{ }^{\circ} \mathrm{C}$ or more within 30 min after sherry was arbitrarily regarded as a positive reaction $\left(1.1^{\circ} \mathrm{C}\right.$ or more were regarded positive by Leslie et al. [3])

\section{Results}

The percentage of positive tests among the various groups of subjects is given in Table 1 . Within the group of normal controls there was no significant difference between the relatives of patients with IDDM (18.9\% positive) and the others $(15.8 \%)$. One family with a clearcut Tattersall syndrome (= Mason type diabetes $[2,4]$ ) is shown in Figure 1. All 7 members of this family in whom the test was performed were $\mathrm{CPAF}$ negative. The frequencies of the diabetes associated HLA-types B $8(44.9 \%)$, B $15(28.6 \%)$ and B $8+$ B $15(8.2 \%)$ among the 49 CPAF-positive IDDM subjects were significantly higher than in normal controls and about equal that in IDDM in general (44.5, 22.4 and 5.4 resp. [5]).

The results of the skin temperature measurements are given in Tables 2 and 3. In most but not all cases an increase of skin temperature correlated with the patients report of a positive flush. In the subjects in whom the tests with skin temperature measurement were performed more than once the reproducibility was limited (Table 4).

\section{Discussion}

Test performance and evaluation in the present study were similar to previous descriptions $[1,2,4,9]$. It was the person's subjective description that determined whether the appropriate response had occurred. Placebo tests seemed not to be essential since only one out of 193 individuals were reported by Leslie and Pyke [1] to react positively to placebo. These authors, who initially had also used $20 \mathrm{ml}$ of sherry [9] later used $40 \mathrm{ml}[1,2]$ but only in very rare cases was a difference in response observed (personal communication).

The results of the present study, however, differ in various aspects from those by Leslie and Pyke [1, 2]. In the present study the frequency of $\mathrm{CPAF}$ is higher among normal controls and IDDM and lower among patients with NIDDM. In addition, no difference was observed between non-insulin dependent 
Table 2. Basal facial skin temperature $\left({ }^{\circ} \mathrm{C}\right)$ and increment after alcohol $(20 \mathrm{ml}$ of sherry) following pretreatment with placebo or chlorpropamide. $+=$ facial flush according to subjective assessment (questionnaire),$-=$ no subjective flush reaction. Other abbreviations as Table 1

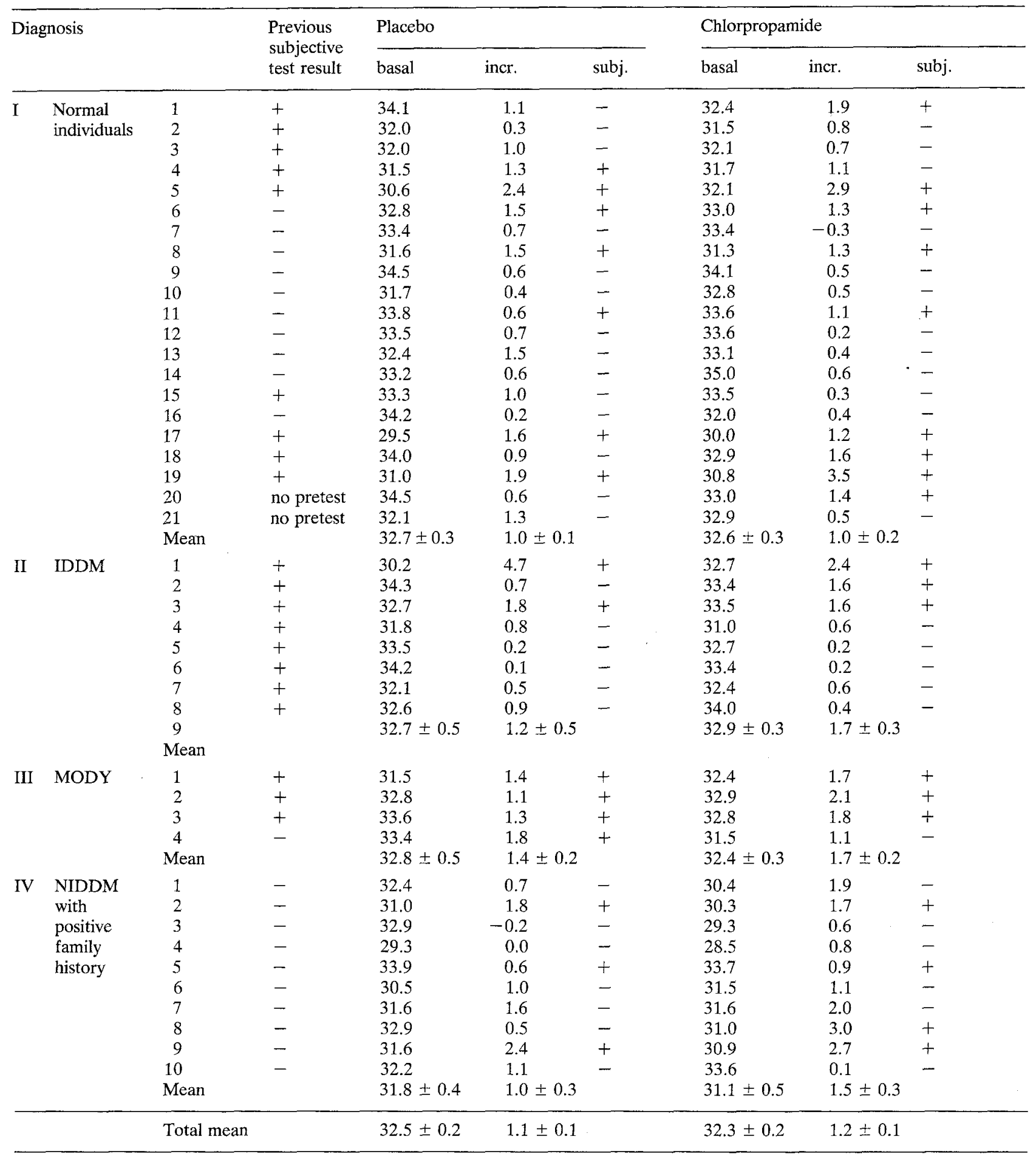


Table 3. Skin temperature rise after $20 \mathrm{ml}$ of sherry following pretreatment with placebo (Pl) or chlorpropamide (Chl) in 21 normal and 22 diabetic subjects. $+=$ increment of $\geq 1.2^{\circ} \mathrm{C},-=$ lower or no increment. Other abbreviations as Table 1

\begin{tabular}{|c|c|c|c|c|c|c|}
\hline & & $\mathrm{n}$ & $\begin{array}{l}\mathrm{Pl}-/ \\
\mathrm{Chl}-\end{array}$ & $\begin{array}{l}\mathrm{Pl}+/ \\
\mathrm{Chl}-\end{array}$ & $\begin{array}{l}\mathrm{Pl}+1 \\
\mathrm{Chl}+\end{array}$ & $\begin{array}{l}\mathrm{Pl}-/ \\
\mathrm{Chl}+\end{array}$ \\
\hline I & $\begin{array}{l}\text { Normal } \\
\text { individuals }\end{array}$ & 21 & 10 & 3 & 5 & 3 \\
\hline II & IDDM & 8 & 5 & 0 & 2 & 1 \\
\hline III & MODY & 4 & 0 & 1 & 2 & 1 \\
\hline \multirow[t]{3}{*}{ IV } & $\begin{array}{l}\text { NIDDM with } \\
\text { positive family }\end{array}$ & & & & & \\
\hline & history & 10 & 5 & 0 & 3 & 2 \\
\hline & Sum & 43 & 20 & 4 & 12 & 7 \\
\hline
\end{tabular}

diabetes with and without a family history of diabetes. The differences between the various groups of the present study are not statistically significant. CPAF therefore seems not to be specific for any special type of diabetes mellitus. This lack of association with NIDDM was also described in a small series (14 normals, 19 diabetics) by other authors [10]. The same HLA-distribution among CPAF-positive and negative patients with IDDM suggests that there is no aetiological difference between these two groups.

Although in most cases a clear assignment as CPAF positive or negative was possible on the basis of subjective test evaluation the reaction is not of an all or none character and it is difficult to define the prerequisites for a positive diagnosis. The reproducbility is limited, as could be observed with repetitive testing of skin temperature increments. The basal skin temperature and thereby the increment [11] may depend on several other influences such as environmental temperature, emotional factors, smoking before the test or further unknown variables. The flush reaction is not specific for a pretreatment with chlorpropamide but we have not performed enough placebo tests to assess whether chlorpropamide increases the sensitivity to small amounts of alcohol in many individuals. Since the subjects tested in the second part of our study were recruited after their subjective flush result was known the results obtained by skin temperature measurements cannot yield true incidence figures.

No plausible explanation can be provided for the differences between the results by Leslie and Pyke

Table 4. Skin temperature measurement $\left({ }^{\circ} \mathrm{C}\right)$ during $30 \mathrm{~min}$ after alcohol $(20 \mathrm{ml}$ of sherry) and pretreatment with placebo $(\mathrm{Pl})$ or chlorpropamide $(\mathrm{Chl})$ in eight individuals with more than two tests. $\mathrm{m}$, male; f, female. Other abbreviations as Table 1

\begin{tabular}{|c|c|c|c|c|c|c|c|c|c|}
\hline Diagnosis & $\begin{array}{l}\text { Present } \\
\text { age }\end{array}$ & Sex & Test & $\begin{array}{l}\text { Flush } \\
\text { according } \\
\text { to question- } \\
\text { naire }\end{array}$ & Basal & $10^{\prime}$ & $20^{\prime}$ & $30^{\prime}$ & Peak increment \\
\hline Normal & 71 & $\mathrm{f}$ & $\begin{array}{l}\text { Chl } \\
\text { Chl } \\
\text { Pl }\end{array}$ & $\begin{array}{l}+ \\
+ \\
+\end{array}$ & $\begin{array}{l}28.6 \\
32.1 \\
30.6\end{array}$ & $\begin{array}{l}29.5 \\
32.7 \\
30.7\end{array}$ & $\begin{array}{l}30.3 \\
34.2 \\
31.6\end{array}$ & $\begin{array}{l}31.2 \\
35.0 \\
33.0\end{array}$ & $\begin{array}{l}2.6 \\
2.9 \\
2.4\end{array}$ \\
\hline Normal & 26 & $\mathrm{f}$ & $\begin{array}{l}\text { Chl } \\
\mathrm{Pl} \\
\mathrm{Chl}\end{array}$ & $\begin{array}{l}+ \\
- \\
-\end{array}$ & $\begin{array}{l}33.0 \\
31.1 \\
30.7\end{array}$ & $\begin{array}{l}33.4 \\
31.7 \\
31.0\end{array}$ & $\begin{array}{l}34.4 \\
31.6 \\
31.1\end{array}$ & $\begin{array}{l}34.4 \\
31.8 \\
31.3\end{array}$ & $\begin{array}{l}1.4 \\
0.7 \\
0.6\end{array}$ \\
\hline IDDM & 19 & $\mathrm{f}$ & $\begin{array}{l}\mathrm{Pl} \\
\mathrm{Pl} \\
\mathrm{Chl}\end{array}$ & $\begin{array}{l}- \\
\overline{+}\end{array}$ & $\begin{array}{l}35.4 \\
34.3 \\
33.4\end{array}$ & $\begin{array}{l}35.1 \\
34.8 \\
34.5\end{array}$ & $\begin{array}{l}35.3 \\
34.9 \\
35.0\end{array}$ & $\begin{array}{l}35.2 \\
34.5 \\
34.6\end{array}$ & $\begin{array}{l}0.1 \\
0.6 \\
1.6\end{array}$ \\
\hline IDDM & 28 & $\mathrm{f}$ & $\begin{array}{l}\mathrm{Chl} \\
\mathrm{Pl} \\
\mathrm{Chl}\end{array}$ & $\begin{array}{l}+ \\
+ \\
+\end{array}$ & $\begin{array}{l}34.2 \\
32.7 \\
33.5\end{array}$ & $\begin{array}{l}35.1 \\
33.3 \\
34.4\end{array}$ & $\begin{array}{l}35.2 \\
34.3 \\
35.1\end{array}$ & $\begin{array}{l}35.4 \\
34.5 \\
34.9\end{array}$ & $\begin{array}{l}1.2 \\
1.8 \\
1.6\end{array}$ \\
\hline NIDDM & 65 & $\mathrm{f}$ & $\begin{array}{l}\mathrm{Pl} \\
\mathrm{Pl} \\
\mathrm{Chl}\end{array}$ & $\begin{array}{l}+ \\
+ \\
+\end{array}$ & $\begin{array}{l}32.7 \\
33.8 \\
33.7\end{array}$ & $\begin{array}{l}33.8 \\
34.9 \\
35.1\end{array}$ & $\begin{array}{l}34.6 \\
35.3 \\
35.2\end{array}$ & $\begin{array}{l}35.2 \\
34.9 \\
34.8\end{array}$ & $\begin{array}{l}2.5 \\
1.5 \\
1.5\end{array}$ \\
\hline MODY & 22 & $\mathrm{f}$ & $\begin{array}{l}\text { Pl } \\
\text { P1 } \\
\text { Chl }\end{array}$ & $\begin{array}{l}- \\
+ \\
+\end{array}$ & $\begin{array}{l}34.0 \\
33.6 \\
32.8\end{array}$ & $\begin{array}{l}34.2 \\
34.7 \\
33.4\end{array}$ & $\begin{array}{l}34.3 \\
34.7 \\
34.2\end{array}$ & $\begin{array}{l}34.2 \\
34.5 \\
34.6\end{array}$ & $\begin{array}{l}0.3 \\
1.1 \\
1.8\end{array}$ \\
\hline MODY & 38 & $\mathrm{~m}$ & $\begin{array}{l}\text { Pl } \\
\text { Chl } \\
\text { Chl }\end{array}$ & $\begin{array}{l}+ \\
+ \\
+\end{array}$ & $\begin{array}{l}32.8 \\
34.5 \\
32.9\end{array}$ & $\begin{array}{l}33.3 \\
35.2 \\
34.4\end{array}$ & $\begin{array}{l}33.5 \\
35.3 \\
34.2\end{array}$ & $\begin{array}{l}33.9 \\
35.2 \\
34.8\end{array}$ & $\begin{array}{l}1.1 \\
0.8 \\
1.9\end{array}$ \\
\hline MODY & 40 & f & $\begin{array}{l}\mathrm{Pl} \\
\mathrm{Pl} \\
\mathrm{Chl}\end{array}$ & $\begin{array}{l}+ \\
+ \\
+\end{array}$ & $\begin{array}{l}30.9 \\
31.5 \\
32.4\end{array}$ & $\begin{array}{l}31.1 \\
32.0 \\
33.0\end{array}$ & $\begin{array}{l}31.6 \\
32.6 \\
34.1\end{array}$ & $\begin{array}{l}31.9 \\
32.9 \\
34.0\end{array}$ & $\begin{array}{l}1.0 \\
1.4 \\
1.6\end{array}$ \\
\hline
\end{tabular}


and our study. Further studies from other authors are needed to clarify whether there is an association of CPAF with a genetic type of NIDDM which we might have missed in our study. We conclude that the test is not suitable for individual diagnosis or for application in genetic counselling.

Acknowledgements. This work was supported by a grant from the Deutsche Forschungsgemeinschaft (Ko 457/9). We thank Prof. W. Creutzfeldt and Dr. U. Deuticke, Dept. of Medicine, University of Göttingen, and Prof. B. Willms, Diabetesklinik Bad Lauterberg, for allowing us to study patients under their care. HLA studies were performed by Dr. Eckert, Medizinische Hochschule Hannover, or by Dr. Neumeyer, Blutbank, University of Göttingen.

\section{References}

1. Leslie RDG, Pyke DA (1978) Chlorpropamide-alcohol flushing: a dominantly inherited trait associated with diabetes. $\mathrm{Br}$ Med J II: 1519-1521

2. Pyke DA, Leslie RDG (1978) Chlorpropamide-alcohol flushing: a definition of its relation to non-insulin dependent diabetes. Br Med J II: 1521-1522

3. Leslie RDG, Pyke DA, Stubbs WA (1979) Sensitivity to enkephalin as a cause of non-insulin dependent diabetes. Lancet I: $341-343$
4. Pyke DA (1979) Diabetes: The genetic connections. Diabetologia 17: 333-343

5. Bengsch N, Köbberling J, Eckert G, Willms B (1978) HLATyping in juvenile diabetics with and without positive family history and in families with one and two diabetic siblings. Diabetologia 15: 447-451

6. Köbberling J, Brüggeboes B (1980) Prevalence of diabetes among children of insulin dependent diabetic mothers. Diabetologia 18: 1-4

7. Tattersall RB (1974) Mild familial diabetes with dominant inheritance. Q J Med 170: 339-357

8. Tattersall RB, Frajans SS (1975) A difference between the inheritance of classical juvenile-onset and maturity-onset type diabetes of young people. Diabetes 1: 44-53

9. Leslie RDG, Pyke DA (1978) Chlorpropamide-alcohol flushing and maturity-onset-diabetes. Diabetologia 14: 250

10. Dreyer M, Kühnau J, Rüdiger HW, Bartelheimer H (1980) Der Chlorpropamid-Alkohol-Flush-Test: Keine Hilfe bei der genetischen Beratung von Diabetikern. Akt Endokrinol I: 171

11. Köbberling J, Weber M (1980) Facial flush after chlorpropamide alcohol and enkephalin. Lancet I: 538- 539

Received: April 21, 1980,

and in revised form: July 1, 1980

Prof. Dr. J. Köbberling

Medizinische Universitätsklinik

Robert-Koch-Straße 40

D-3400 Göttingen

Federal Republic of Germany 